\title{
ge
}

ARTIGOS

\section{DA INFORMALIDADE AO CIRCUITO INFERIOR: UM ESTUDO SOBRE A ECONOMIA URBANA EM GANA NO INÍCIO DO SÉCULO XXI}

Kauê Lopes dos Santos ${ }^{1}$

Universidade de São Paulo

London School of Economics and Political Science

Enviado em 20 out. 2019 | Aceito em 27 set. 2020

Resumo: Desenvolvidos nos anos 1970, os conceitos de informalidade e circuito inferior - criados, respectivamente, pelo antropólogo britânico Keith Hart e pelo geógrafo brasileiro Milton Santos - integravam teorias que buscavam interpretar a economia urbana dos países que pertenciam ao então denominado Terceiro Mundo. Partindo das contribuições desses autores, este artigo busca analisar a organização contemporânea da economia urbana de Gana, país localizado na África Ocidental. Os dados quantitativos e qualitativos utilizados neste estudo foram obtidos por meio de fontes secundárias (livros, artigos e relatórios setoriais) e primárias (entrevistas semiestruturadas, descrição densa e registros da paisagem), as quais permitiram não apenas reiterar o vigor interpretativo das proposições de Hart (1973) e Santos (1975) como também revelar o dinamismo contemporâneo da economia urbana do país em questão, composto por atividades que operam em múltiplas escalas geográficas, segundo diferentes níveis de organização e capital investido.

Palavras-chave: economia urbana; informalidade; circuito inferior; urbanização africana; Sul Global

FROM INFORMALITY TO THE LOWER CIRCUIT: A STUDY ON GHANA'S URBAN ECONOMY IN THE EARLY 21ST CENTURY Abstract: Developed in the 1970s, the concepts of informality and lower circuit - created respectively by the British anthropologist Keith Hart and by the Brazilian geographer Milton Santos - integrated theories aimed at interpreting the urban economy of countries that belonged to the so-called Third World. Based on the contributions of these authors, this article seeks to analyze the organization of the contemporary urban economy of Ghana, a country located in West Africa. The quantitative and qualitative data used in this study were obtained from secondary sources (books, articles and sectoral reports) and primary ones (semi-structured interviews, dense description and landscape records), which allowed not only to reiterate the vigor of Hart (1973) and Santos' (1975) propositions as well as revealing the contemporary dynamics of the urban economy of the studied country, composed of activities that operate on multiple geographical scales, according to different levels of organization and invested capital.

Keywords: urban economy; informality; lower circuit; African urbanization; Global South

DE L'INFORMALITE AU CIRCUIT INFERIEUR: UNE ETUDE SUR L'ECONOMIE URBAINE DU GHANA AU DEBUT DU 21E SIECLE Résumé: Développés dans les années 1970, les concepts d'informalité et de circuit inférieur - créés respectivement par l'anthropologue britannique Keith Hart et par le géographe brésilien Milton Santos - ont intégré des théories visant à interpréter l'économie urbaine dans des pays appartenant à la soi-disant Troisième Monde. À partir des contributions de ces auteurs, cet article cherche à analyser l'organisation de l'économie urbaine contemporaine du Ghana, un pays situé en Afrique de l'Ouest. Les informations quantitatives et qualitatives utilisées dans cette étude ont été obtenues à partir de sources secondaires (livres, articles et rapports sectoriels) et primaires (entretiens semi-structurés, description dense et fiches paysagères), qui ont permis non seulement de réitérer la vigueur de Hart (1973 ) et Santos (1975) ainsi que de révéler la dynamique contemporaine de l'économie urbaine du pays étudié, composée d'activités qui opèrent à multiples échelles géographiques, selon différents niveaux d'organisation et de capital investi.

Mots clés: économie urbaine; informalité; circuit inférieur; L'urbanisation africaine; Sud global

\footnotetext{
1. Doutor em Geografia Humana pela Universidade de São Paulo. Atualmente é Pesquisador de Pós-Doutorado na Universidade de São Paulo e Pesquisador Visitante na London School of Economics and Political Science. ORCID: https://orcid.org/0000-0001-9996-1079.Email: kauegeo@gmail.com.
} 
Introdução

Repensar a "geografia" das teorias urbanas e regionais é uma premissa contemporânea de extrema relevância levantada por Ananya Roy em seu artigo intitulado A metrópole do século XXI (ROY, 2009, p.820, tradução do autor). De acordo com a perspectiva da urbanista indiana, deslocar o centro tornou-se uma necessidade axial diante da atual extensão e complexidade do processo de urbanização nos territórios do Sul Global. A autora afirma que tal necessidade se aplica especialmente aos estudiosos que ainda concebem as teorias urbanas e regionais somente a partir das experiências do Norte Global. Um argumento similar ao de Roy foi levantado há mais de quarenta anos por Milton Santos em seu livro o espaço dividido: os dois circuitos da economia urbana dos países subdesenvolvidos, publicado originariamente em francês (L'espace partagé: les deux circuits de l'économie urbaine des pays sous-développés) no ano de 1975. De acordo com o geógrafo brasileiro, existem problemas metodológicos significativos quando os acadêmicos das cientistas sociais e humanas tentam analisar os espaços urbanos africanos, latino-americanos e asiáticos por meio da instrumentalização de teorias baseadas nas cidades da Europa e da América Anglo-saxônica.

A economia urbana da maior parte dos territórios do Sul Global - considerando aqui não apenas os países que integravam o chamado Terceiro Mundo nas décadas de 1960, 70 e 80, mas também aqueles que integravam o Segundo Mundo na condição de periferia ou semiperiferia do sistema mundo na mesma época (WALLERSTEIN, 2007) - tem sido objeto de estudo entre antropólogos, sociólogos, economistas, geógrafos e urbanistas desde, pelo menos, a década de 1950. Grande parte das problemáticas levantadas acerca desse tema debruçaram-se em análises e formulações teóricas sobre a organização e as dinâmicas das variadas atividades econômicas em cidades localizadas na África, na América Latina e na Ásia.

Localizada na África Ocidental, Gana possui um conjunto de cidades em seu território que é, na atualidade, o locus de uma vigorosa vida econômica que torna a paisagem urbana do país um fiel registro das atividades manufatureiras, comerciais e de serviços. Com o objetivo de interpretar a organização e o dinamismo dessa economia no início do século XXI, este artigo lançará mão de duas importantes perspectivas analíticas desenvolvidas na década de 1970: a classificação das atividades a partir do binômio formalidade-informalidade do antropólogo inglês Keith Hart (HART, 1973) e; a teoria dos dois circuitos da economia urbana do geógrafo brasileiro Milton Santos (SANTOS, 1975; 2004).

Para viabilizar esse objetivo, este artigo está baseado na análise de fontes secundárias e primárias. Na medida em que livros, artigos e relatórios setoriais foram responsáveis pelo levantamento de dados quantitativos e qualitativos (especialmente daqueles postos em perspectiva histórica), foram realizados também diversos trabalhos de campo entre 2013 e 2016 nas cidades de Acra, Kumasi, Tamale, Takoradi e Cape Coast, de modo que registros fotográficos, registros descritivos (descrição densa) e entrevistas semiestruturadas adensaram os dados qualitativos da pesquisa.

\section{Da urbanização africana ao mundo urbano de Gana}

Antes de adentrar o universo da economia urbana ganense contemporânea, é fundamental estabelecer uma breve contextualização histórica sobre as cidades em África, dado que as aglomerações urbanas nesse continente datam de centenas de anos e, em grande parte das vezes, 
estiveram associadas aos centros dos grandes reinos e impérios. Segundo o historiador ganense Albert Adu Boahen, a vida urbana desenvolvia-se em muitas localidades:

[...] Os reinos e impérios africanos possuíam capitais e centros políticos como Kumbi Saleh, Benin, Ile-Ife, Kumasi, Gao, e Zimbábue, além de centros comerciais como Kano, Jenne, Sofala e Melinde. Havia também centros educacionais como Tombuctu, Cairo e Fez (BOAHEN, 2010, p.935).

Esses espaços urbanos estiveram associados às funções políticas, econômicas e culturais de territórios soberanos até a colonização do continente pelas potências imperialistas europeias, ocorrida em fins do século XIX. A partir de então, mudanças significativas ocorreram nos padrões da urbanização africana. Segundo o historiador congolês Elikia M'Bokolo:

[...] A colonização alterou totalmente o movimento da urbanização e a paisagem urbana da África em função de suas próprias necessidades. Cidades antigas como Gao, Kukuwa ou Abeche, terminais do comércio transaariano, ou Kong e Salaga, encruzilhadas de um comércio inter-regional, soçobraram num declínio irreversível. Outras, como Kano ou Uagadugu, foram recuperadas e desenvolvidas pela economia colonial. Outras ainda, como Gorée, Porto-Novo e Cape Coast, florões da época do tráfico negreiro, foram abandonadas. Algumas feitorias menos antigas, como Saint-Louis, Libreville e Lagos, e os portos que, no passado, tinham estado virados para o comércio com a Ásia, Mombaça e Zanzibar, prosseguiram a sua expansão numa nova dinâmica. Mas sobretudo, a colonização redundou na criação de novas cidades a partir do nada (M'BOKOLO, 2011, p.500-501).

M'Bokolo salienta ainda que as cidades criadas durante o período colonial estiveram fundamentalmente associadas às funções econômicas, especialmente entorno dos portos (como nos casos Dacar, Conakry, Pointe-Noire, Kaolack, Mbandaka) e das áreas de extração de minérios (as chamadas townships, localizadas principalmente na África Central e Austral (M'BOKOLO, 2011).

Essas cidades vinculadas ao empreendimento colonial passaram, a partir de então, a refletir materialmente uma segregação de ordem racial. Criaram-se bairros planejados e dotados de infraestruturas e serviços urbanos reservado às populações brancas colonizadoras, ao passo que a maioria restante da população local se concentrava em bairros periféricos de materialidade precária e de marcadas condições de insalubridade (M'BOKOLO, 2011).

O aumento da população urbana impulsionado pelo êxodo rural ocorrido durante o período colonial - êxodo esse estimulado pela oferta de trabalho na construção civil e em atividades de comércio e serviços diversos - intensificou-se a partir das independências nacionais, que se iniciaram em meados do século XX. Nas décadas de 1960, 70 e 80, esse êxodo foi promovido principalmente pelas políticas de industrialização de muitos países que, na condição de recém independentes, buscaram desenvolver suas economias nacionais através da substituição de importações. Esse processo gerou um marcado adensamento populacional nas cidades, especialmente nas capitais nacionais, e foi intensificado pela queda na taxa de mortalidade - graças aos avanços da medicina e os investimentos em infraestruturas de saúde pública - e, também, pela manutenção das elevadas taxas de natalidade e fertilidade da população no continente. A Organização das Nações Unidas estimou, em 1981, que entre 1950 e 1980, a população urbana africana tenha saltado de 14,5 para 28,9\% (KIPRÉ, 2010).

Ainda que os projetos de substituição de importações tenham sido parcialmente abandonados diante do cenário de recessão econômica na década de 1980, os países africanos chegam ao século XXI apresentando as maiores taxas de urbanização do mundo, mesmo que, em média, $60 \%$ de sua população ainda habite o espaço rural e trabalhe em atividades a ele relacionadas (GRANT, 2015). Em Gana, no entanto, a maioria da população (56\%) vive em espaços urbanos (GHANA STATISTICAL 
SERVICE, 2020), especialmente naqueles localizados nas porções central e meridional do país (Croqui Cartográfico 1).

Dentre as maiores cidades ganenses, pode-se mencionar: Acra, com 2,2 milhões de habitantes (Região da Grande Acra); Kumasi, com 2 milhões de habitantes (Região Ashanti); Tamale, com 564 mil habitantes (Região Norte); Sekondi-Takoradi, com 445 mil habitantes (Região Oeste); Sunyani, com 248 mil habitantes (Região Brong-Ahafo) e; Cape Coast, com 227 mil habitantes (Região Central) (GHANA STATISTICAL SERVICE, 2020).

Croqui Cartográfico 1 - Regiões e densidade demográfica em Gana (2017)

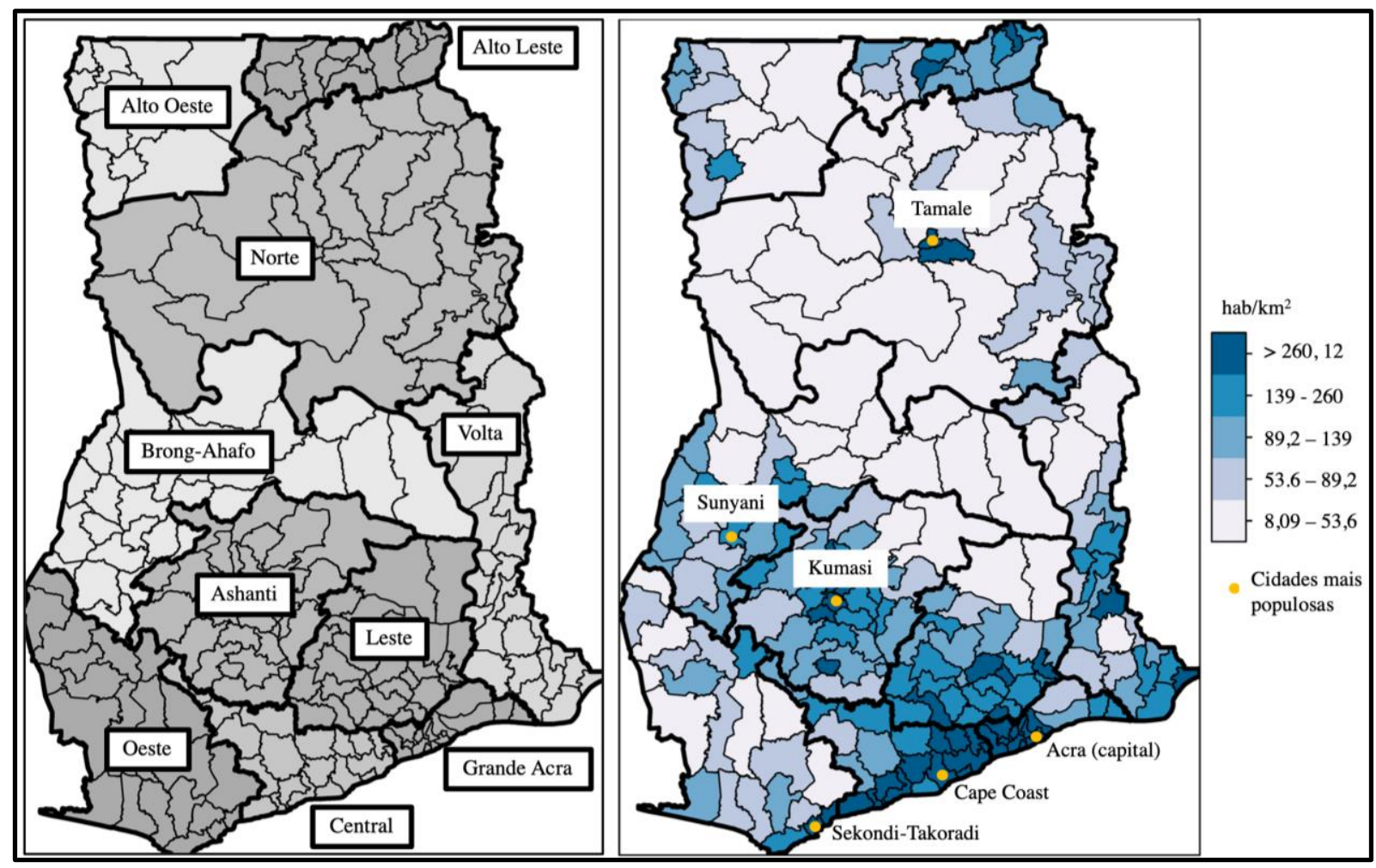

Fonte: Adaptado de OSEI, STEIN E NYADANU, 2018.

Em 2017, a População Economicamente Ativa (PEA) de Gana estava estimada em 12,5 milhões de pessoas, das quais 14,4\% estavam ocupadas na indústria e 40,9\% nos serviços, sendo ambas atividades tradicionalmente urbanas. No mesmo ano, verificou-se a importância desses setores secundário e terciário - na arrecadação de mais de 80\% do Produto Interno Bruto (PIB): as atividades industriais corresponderam a $24,5 \%$ do PIB; e as atividades de serviços geraram $57,2 \%$ das riquezas do país, revelando o peso das cidades na economia nacional (GHANA STATISTICAL SERVICE, 2020). Interessa agora interpretar a organização da economia urbana ganense, particularmente em suas maiores cidades.

\section{Metodologia}

Atentando ao objetivo levantado na introdução deste artigo, a metodologia de pesquisa deste estudo estruturou-se na coleta e análise de dados qualitativos e quantitativos, os quais foram obtidos em fontes primárias e secundárias. 
Desde 2013 foram realizadas cinquenta entrevistas semiestruturadas com trabalhadores (e/ou proprietários) de diferentes atividades econômicas nas cidades de Acra (20 entrevistas), Kumasi (10), Takoradi (10) e Tamale (10). O roteiro de questões buscou identificar as condições gerais de organização interna, capitalização e abrangência espacial da atuação das atividades. Dentre elas, pode-se mencionar: comércio em pequenos estabelecimentos (bazares e mercearias), comércio ambulante e pequenas manufaturas (de tecido e de farinha de banana e mandioca). Registros escritos também foram desenvolvidos na forma de descrição densa (GEERTZ, 1973), especialmente nos maiores mercados de Acra (Mercado Makola I e II) e de Kumasi (Mercado Kejetia). As paisagens urbanas foram registradas por meio de fotografias.

Estabelecendo um diálogo com os dados qualitativos coletados e analisados, as informações de ordem quantitativa sobre a economia urbana de Gana foram obtidas principalmente por meio de anuários estatísticos publicados pelo Serviço Estatístico de Gana (Ghana Statistical Service), além de artigos acadêmicos e livros sobre a economia do país.

Os trabalhos de referência teórica responsáveis pela estruturação da metodologia desta pesquisa são o artigo de Keith Hart intitulado Informal Income Opportunities and Urban Employment in Ghana (publicado em 1973 no The Journal of Modern African Studies) e o livro de Milton Santos O espaço dividido (publicado em 2004, ainda que a primeira edição em português seja 1979 e a primeira edição em francês seja de 1975).

\title{
Os setores formal-informal e a economia urbana ganense
}

A partir da década de 1970, as noções de formalidade e informalidade foram gradativamente incorporadas aos estudos de economia urbana, principalmente nas análises que se debruçavam sobre a realidade de países africanos, latino-americanos e asiáticos. A elaboração da classificação em questão pode ser atribuída ao antropólogo inglês Keith Hart, quando este realizou seus estudos acerca das cidades ganenses na década de 1970. Nesse contexto espaço-temporal, Hart estabeleceu a distinção entre aquilo que denominou setor formal e setor informal da economia:

\begin{abstract}
A variável-chave [de diferenciação] é o grau de racionalização do trabalho, o que significa dizer se o trabalho é, ou não, recrutado em uma base regular por recompensas estáveis. A maioria das empresas que operam em certo nível de burocratização é passível de ser enumerada por pesquisas e constituem o "setor moderno" da economia. O restante - por assim dizer aqueles que escapam da enumeração - é classificado de forma variada como "setor urbano de baixa produtividade", "exército de reserva de subempregados e desempregados", "setor urbano tradicional" etc. (HART, 1973, p.68, tradução do autor).
\end{abstract}

Na época, o antropólogo chamava atenção para a notória predominância do setor informal nas cidades ganenses. Em sua análise, este setor seria composto por numerosas e variadas atividades que, em oposição ao setor moderno (sinônimo de setor formal), operavam em condições menos regulares de recrutamento da força de trabalho, representando uma geração de valor menos estável, ainda que nada desprezível (HART, 1973). No universo da informalidade, o trabalho poderia ser assalariado ou autônomo.

O pioneirismo do estudo de Hart esteve também na análise relacional que este estabeleceu entre os setores formal e informal: o antropólogo caracterizou como algumas pequenas empresas de transporte de carga - que operavam na informalidade - eram contratadas por grandes indústrias de mineração (HART, 1973), denotando não apenas a articulação entre empresas de diferentes níveis de capitalização, mas também como algumas atividades informais eram capazes de atuar em escalas regionais e nacionais, articuladas à economia de exportação. 
$\mathrm{Na}$ medida em que foi sendo difundida e instrumentalizada por institutos de pesquisas socioeconômicas e instituições financeiras, a setorização desenvolvida por Hart foi gradativamente perdendo seu potencial interpretativo e analítico, sendo tornada, no final do século XX, um aspecto classificatório rígido da economia urbana em nome da preocupação dos governos nacionais em registrar e combater a informalidade, entendida como um problema para a arrecadação do Estado. Segundo o Banco Mundial:

A economia informal se refere às atividades e rendas que são parcialmente ou totalmente externas às regulações, taxas e registros governamentais. A principal razão da economia não declarada é financeira. Esse tipo de atividade permite que empregadores, empregados e autônomos aumentem suas receitas ou reduzam seus custos por meio da evasão de taxações e contribuições sociais (BANCO MUNDIAL, 2020 s/p).

Dentro dessa perspectiva, o Serviço Estatístico de Gana estabelece que as condições de formalidade e informalidade sejam definidas a partir do registro (ou do não registro, no caso da informalidade) de um determinado empreendimento no Departamento Geral de Registros (DGR) (GHANA STATISTICAL SERVICE, 2020).

Todos os proprietários e trabalhadores entrevistados durante os trabalhos de campo operavam em situação de informalidade. Não estando registrados no DGR - alegando o alto custo das taxas que devem ser pagas ao governo -, eles também revelaram alguns dos efeitos adversos decorrentes dessa condição normativa. Um desses efeitos é o acesso limitado ao crédito formal, que foi mencionado por dois donos de manufaturas têxteis:

Nenhum banco quer me dar dinheiro para comprar máquinas. A saída que eu encontrei foi pedir crédito pessoal, como se eu fosse comprar alguma coisa no mercado para mim. Eu sei que a dívida fica no meu nome, mas pelo menos eu posso usar o dinheiro para investir na minha atividade (Entrevistado 5, proprietário de uma pequena fábrica de tecidos em Acra, em entrevista concedida em fevereiro de 2016).

Tive que aumentar meu fluxo de caixa para poder comprar máquinas. O banco não é uma opção. Nem a ajuda governamental. O que venho fazendo é abrir minha fábrica para a visitação de turistas. Muitos deles já compram os panos kente [um tipo de tecido tradicional da Região Ashanti] das minhas mãos (Entrevistado 11, dono de uma pequena fábrica de tecidos kente em Kumasi, em entrevista concedida em fevereiro de 2016).

A dificuldade de acesso ao crédito formal oferecido pelos bancos obrigou dois dos entrevistados a encontrarem estratégias alternativas de obtenção de capital, como a contratação de crédito pessoal e o aumento do fluxo de caixa com atividades paralelas (como abertura das áreas de produção para visitação de turistas).

Na atualidade, a economia urbana ganense ainda se mantém marcadamente informal, de modo que o setor agrupa aproximadamente $90 \%$ dos estabelecimentos empresariais nas cidades do país (GHANA STATISTICAL SERVICE, 2020). Aos olhos do governo, isso significa um elevado percentual de empreendimentos que estão à margem do sistema tributário e, justamente por isso, inviabilizados de acessar crédito em instituições financeiras (públicas e privadas) ou contratos com outras empresas, incluindo possíveis joint ventures com o capital estatal. Essa informação ajuda a entender a dimensão normativa-regulatória da economia urbana ganense contemporânea. No entanto, dado o objetivo deste artigo, entende-se que a teoria dos dois circuitos da economia urbana oferece um vigoroso referencial interpretativo sobre a organização e as dinâmicas dessa economia para além do entendimento atual do binômio formalidade-informalidade. 
Para Santos, as abordagens teóricas da urbanização em territórios terceiro-mundistas começaram a ser elaboradas, de maneira mais sistemática, a partir da década de 1950, através dos esforços empreendidos principalmente por economistas e sociólogos. Em meio aos escassos materiais estatísticos produzidos sobre esses países até então, as análises realizadas ficavam restritas a adjetivações das cidades estudadas ou a tentativas artificiais de adequá-las a modelos quantitativos e a teorias feitas para as cidades da Europa e dos Estados Unidos (SANTOS, 2004).

Rapidamente esses esforços mostraram sua inadequação às especificidades dos territórios africanos, asiáticos e latino-americanos. Foi somente na década de 1970, em virtude de um maior acúmulo de conhecimento sobre os processos urbanos pelos quais passavam as cidades do Terceiro Mundo, que houve o desenvolvimento de estudos mais precisos sobre os dinamismos de seus espaços e suas economias urbanas (SANTOS, 2004). Assim, nesse contexto, Santos criou a teoria dos circuitos, que entende a formalidade e a informalidade como aspectos constitutivos, e não definitivos ou taxonômicos, da organização e da dinâmica da economia nas cidades dos países terceiro-mundistas.

\section{A teoria dos circuitos e a economia urbana ganense}

De acordo com a teoria de Santos, a economia urbana nos países, hoje considerados, Sul Global pode ser interpretada a partir da formação de dois circuitos distintos, porém complementares: o circuito superior (CS) e o circuito inferior (CI) (SANTOS, 2004).

Por um lado, o CS compreende empresas de elevado grau de organização e capitalização, como as grandes indústrias e bancos (sobretudo internacionais), além de grandes empresas de comércio (varejo ou atacado) que atuam nas escalas regional, nacional e muitas vezes internacional. Nesse circuito, o uso do capital é intensivo e a organização das atividades é extremamente burocratizada. 0 emprego geralmente é reduzido, assalariado e formal e opta-se, recorrentemente, pela terceirização de alguns serviços. Além disso, quando necessário, essas atividades fazem estoque em grande quantidade e alta qualidade, já que dispõem de infraestrutura adequada para tanto. Esse circuito também conta com fácil acesso ao crédito formal por parte das instituições financeiras tanto públicas quanto privadas (SANTOS, 2004). Historicamente observa-se que o Estado tem grande influência no desenvolvimento desse circuito, oferecendo isenções fiscais e as infraestruturas necessárias ao funcionamento das cadeias produtivas das quais integra.

Na economia urbana ganense o CS é notoriamente minoritário, sendo representado por bancos, grandes indústrias e redes de varejo (nacionais ou estrangeiras) que, em função da alta capitalização, contam com uma significativa mobilidade territorial, podendo escolher as parcelas do espaço que lhe oferecem maior acessibilidade aos consumidores, fornecedores de matéria-prima, como as porções centro-sul do território. No âmbito da força de trabalho, por mais que essas grandes empresas historicamente atraiam mão de obra de diversas partes do país (incluindo aí as áreas rurais), elas são incapazes de absorver a totalidade de trabalhadores urbanos, levando a formação do chamado exército industrial de reserva, o qual contribui para o desemprego e para o rebaixamento do valor da força de trabalho no mercado.

Como resultado desse processo, outras atividades passam a ganhar visibilidade no espaço urbano, especialmente em centralidades de consumo popular. Trata-se de empreendimentos de menor capitalização e de organização menos burocrática que visam atender justamente as demandas de trabalho e consumo das classes sociais de menor poder aquisitivo, formando o chamado circuito inferior (SANTOS, 2004). 
Esse circuito, por sua vez, conta com o trabalho intensivo de seus funcionários. Em Gana, essas atividades são fundamentalmente informais e ocupam expressiva parcela da força de trabalho urbana. É fundamental salientar que o circuito inferior não é sinônimo de informalidade, por mais que o trabalho informal seja um aspecto presente na maior parte dos seus empreendimentos. Desse modo, o que define a análise da economia urbana a partir da teoria dos dois circuitos é o nível de organização (inclusive tecnológica) e capitalização das atividades econômicas, o que, certamente, são fatores que facilitam ou dificultam o acesso ao trabalho formal.

Em função do reduzido espaço físico de seus estabelecimentos - comerciais, de serviços ou de manufatura - os empreendimentos do $\mathrm{Cl}$ fazem pouco, ou nenhum, estoque. O preço das mercadorias e serviços não é fixo, como no CS, mas sim algo a ser discutido e negociado na relação entre vendedor e consumidor, de modo que a relação com a clientela ganha um tom marcadamente personalizado. Além disso, o ganho é elevado por unidade de produto, mas pequeno em relação ao volume dos negócios (SANTOS, 2004).

Em Gana, o Cl não conta com o mesmo apoio do Estado se comparado aos grandes empreendedores. Isso significa que as atividades do circuito e seus trabalhadores contam com pouco ou nenhum reconhecimento público e possuem dificuldade de acesso a linhas de crédito formal e a seguridade social. Além disso, o $\mathrm{Cl}$ tornou-se historicamente um verdadeiro refúgio para a população pobre desempregada em um país onde, em 2015, 24\% da população vivia abaixo da linha da pobreza e aproximadamente $12 \%$ encontrava-se sem trabalho (GHANA STATISTICAL SERVICE, 2020).

Predomina na economia urbana ganense um circuito inferior no qual grande parte dos trabalhadores são autônomos ou membros de uma empresa familiar. Alguns exemplos de atividades nesse circuito são: pequenos estabelecimentos comerciais, como mercearias, padarias, mercadinhos, armarinhos, papelarias, dentre outros; pequenas fábricas e oficinas de conserto, como borracharias, mecânicas, lojas de reparo de eletrodomésticos e eletroeletrônicos, costureiras; além dos estabelecimentos de serviços de manicure, cabelereiros, barbeiros, moto-táxis etc. (SANTOS, 2017). Nos países do Sul Global, essas atividades geralmente apresentam uma abrangência de atuação local ou regional. No entanto, não apenas em Gana, mas em toda a África Ocidental, muitas atividades do $\mathrm{Cl}$ chegam a alcançar as escalas nacional e internacional, como no caso das empresas de transporte, responsáveis pela circulação material (de pessoas e mercadorias).

A área relativamente pequena do território ganense $\left(238 \mathrm{mil} \mathrm{km}^{2}\right)$ associada a distribuição de infraestruturas de circulação predominantemente rodoviárias (40 mil km de vias pavimentadas e não pavimentadas) permitiram o surgimento de pequenas empresas de transportes (de mercadorias e pessoas) que operam em todo o país (GHANA STATISTICAL SERVICE, 2020). Suprindo a ausência de transporte públicos, esses empreendimentos geralmente funcionam com horários flexíveis, a partir da demanda: tanto em viagens intramunicipais quanto em viagens intermunicipais, os motoristas e cobradores aguardam a lotação máxima de seus veículos (micro-ônibus o ônibus) para dar início a jornada.

Já no que diz respeito a circulação das finanças, a condição de informalidade que predomina nas atividades do circuito inferior dificulta o acesso a linhas de crédito formal, conforme mencionado anteriormente. Esse fato, quando associado à baixa taxa de bancarização da população (58\%), evidencia uma também baixa capilaridade do sistema financeiro na economia urbana do país (BANCO MUNDIAL, 2020). O dinheiro em papel é a forma predominante de circulação de valor, seja ele utilizado para compra de equipamentos, instrumentos, mercadorias, ou para o pagamento de salários e serviços.

Ainda que a circulação das finanças seja limitada, deve ser mencionado que a circulação de informações - por meio da utilização de aparelhos de telefonia móvel (em modalidade de linhas pré- 
paga) - tornou-se marcante nos últimos anos. Possuindo 137,5 linhas ativas para cada 100 habitantes no país em 2018 (BANCO MUNDIAL, 2020), a telefonia móvel tem sido o principal vetor de inserção da economia urbana ganense nas inovações oriundas da Terceira Revolução Industrial. Essa forma de comunicação tem viabilizado uma maior agilidade no estabelecimento de acordos e transações das múltiplas atividades econômicas menos capitalizadas. Além disso, esse dado revela também uma articulação entre os dois circuitos, dado que as empresas de telefonia móvel que operam no país podem ser entendidas como integrantes do circuito superior, como a ganense MTN Ghana, a sueca Tigo (do grupo Millicom) e a indiana Airtel (SANTOS, 2017).

Dados alguns aspectos gerais da economia urbana de Gana, importa agora caracterizar as atividades de manufatura e prestação de serviços - segundo seus níveis de organização e capitalização - e interpretar parte das múltiplas relações que essas atividades estabelecem entre si.

\section{Circuitos da economia e as atividades manufatureiras}

As atividades manufatureiras ganenses foram profundamente impactadas pela crise econômica do final da década de 1970 e pela a subsequente implementação de uma agenda neoliberal no país, a partir de 1983. Nas últimas décadas, essa agenda fomentou um conjunto de políticas econômicas que foi gradativamente deixand o a manufatura nacional em segundo plano, de modo que, em 2014, elas foram responsáveis por apenas 5,7\% do PIB (INSTITUTE OF STATISTICAL, SOCIAL AND ECONOMIC RESEARCH, 2015).

Em linhas gerais, na origem, o processo de desenvolvimento de manufaturas em Gana esteve incorporado aos projetos de industrialização de Kwame Nkrumah - líder da independência em 1957 e presidente entre os anos 1960 e 1966 -, que implementou a política de substituição de importações na década de 1960. Nas palavras do geógrafo ganense Paul Yankson,

[...] a estratégia [de industrialização] envolveu mais a confiança no controle administrativo [estatal] do que nos mecanismos de mercado para determinar as alocações dos recursos; e a confiança, em grande medida, dos investimentos do setor público através de um plano de desenvolvimento de médio prazo liderado pela indústria (YANKSON, 2006, p.8, tradução do autor).

Além desse processo ter sido conduzido pelo Estado, como revela Yankson, ele ocorreu de maneira espacialmente seletiva, com o posicionamento do CS das grandes indústrias manufatureiras nas porções centro-sul do país: no eixo Acra-Tema, em Kumasi e em Takoradi (YANKSON, 2006). Desse modo, as indústrias mais capitalizadas - incluindo as estatais - importavam bens de capital e gozaram, até meados da década de 1970, de volumosos subsídios públicos para financiar suas importações. Isso ocorreu também em um cenário cambial favorável - com a moeda nacional, o cedi, artificialmente valorizado em relação ao dólar - que, por fim, dificultava a entrada de produtos manufaturados estrangeiros no país. Destacavam-se, nesse circuito, indústrias de bens de produção, especialmente aquelas de cimento, tintas, estruturas metálicas e algumas metalúrgicas (RIMMER, 1992).

Ao mesmo tempo, as pequenas manufaturas (Cl) também foram de grande importância na geração de riquezas no setor secundário ganense e, assim como as grandes, elas concentravam-se nas porções centro-sul do território. Essas fábricas possuíam uma tecnologia por vezes importada, mas certamente obsoleta (com o uso frequente de máquinas de segunda-mão) e se dedicavam principalmente à produção de alimentos (farinhas, biscoitos etc.), bebidas, roupas, sapatos, cosméticos e remédios (BOATENG, 1959). 
A manufatura cresceu em importância percentual no país entre a década de 1960 e meados da década de 1970, passando de 13\% do PIB em 1970 para 21\% em 1977. Além disso, na década de 1960, estimulado pela manufatura, o setor industrial registrou o segundo maior crescimento na oferta de empregos, atrás apenas do setor de serviços. Essa oferta operou um maciço êxodo rural, em especial de agricultores das áreas mais pobres, localizadas no norte do país. Contudo, a crise econômica internacional da década de 1970 e o cenário recessivo da década de 1980 impactaram profundamente essa atividade, sobretudo em função da redução dos investimentos públicos e da alta dependência da importação de bens intermediários e bens de capital, o que gerou a gradativa precarização das plantas fabris e dos parques industriais (Figura 1) nas décadas seguintes (HUTCHFUL, 2002).

Figura 1 - Fábrica de chocolate abandonada em Acra, Região da Grande Acra, Gana (2016)

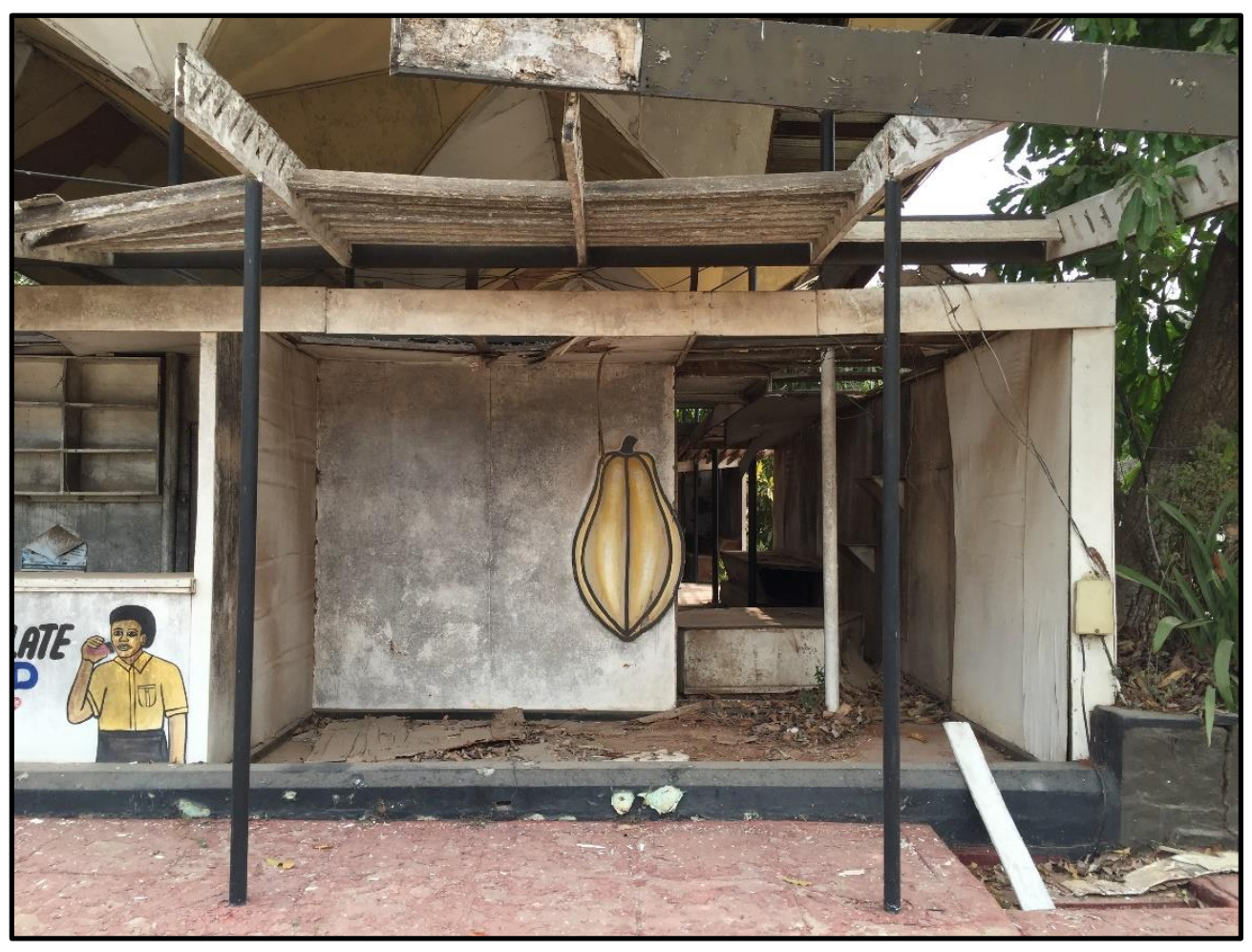

Fonte: elaboração do autor, 2016

Na década de 1980, um conjunto de políticas neoliberais - implementadas durante o governo de Jerry Rawlings, que governou o país entre 1981 e 2001 -, buscou a reanimação do setor secundário por meio de uma série de medidas que visavam intensificar o uso da capacidade ociosa das indústrias e facilitar a entrada de investimentos externos. De modo geral, entre 1984 e 1991, o setor voltou a crescer na média de $8,6 \%$ ao ano. No entanto, essa taxa de crescimento esteve atrelada à entrada de investimentos no curto prazo, de forma que a manufatura - que crescia em média 8,8\% entre 1984 e 1991 - passou a crescer cerca de 3\% a partir de 1991 (HUTCHFUL, 2002).

Em 2015, o número de estabelecimentos classificados como manufaturas pelo Serviço Estatístico de Gana era de aproximadamente 99 mil - o que equivalia a 91,9\% dos estabelecimentos do setor secundário no país - que se concentraram principalmente na Região da Grande Acra (23,4\%), na Região Ashanti (19,6\%) e na Região Oeste (9,2\%), todas localizadas nas porções centro sul (Gráfico 1) (GHANA STATISTICAL SERVICE, 2020). 
Gráfico 1 - Distribuição regional dos estabelecimentos manufatureiros (em \%), Gana (2015)

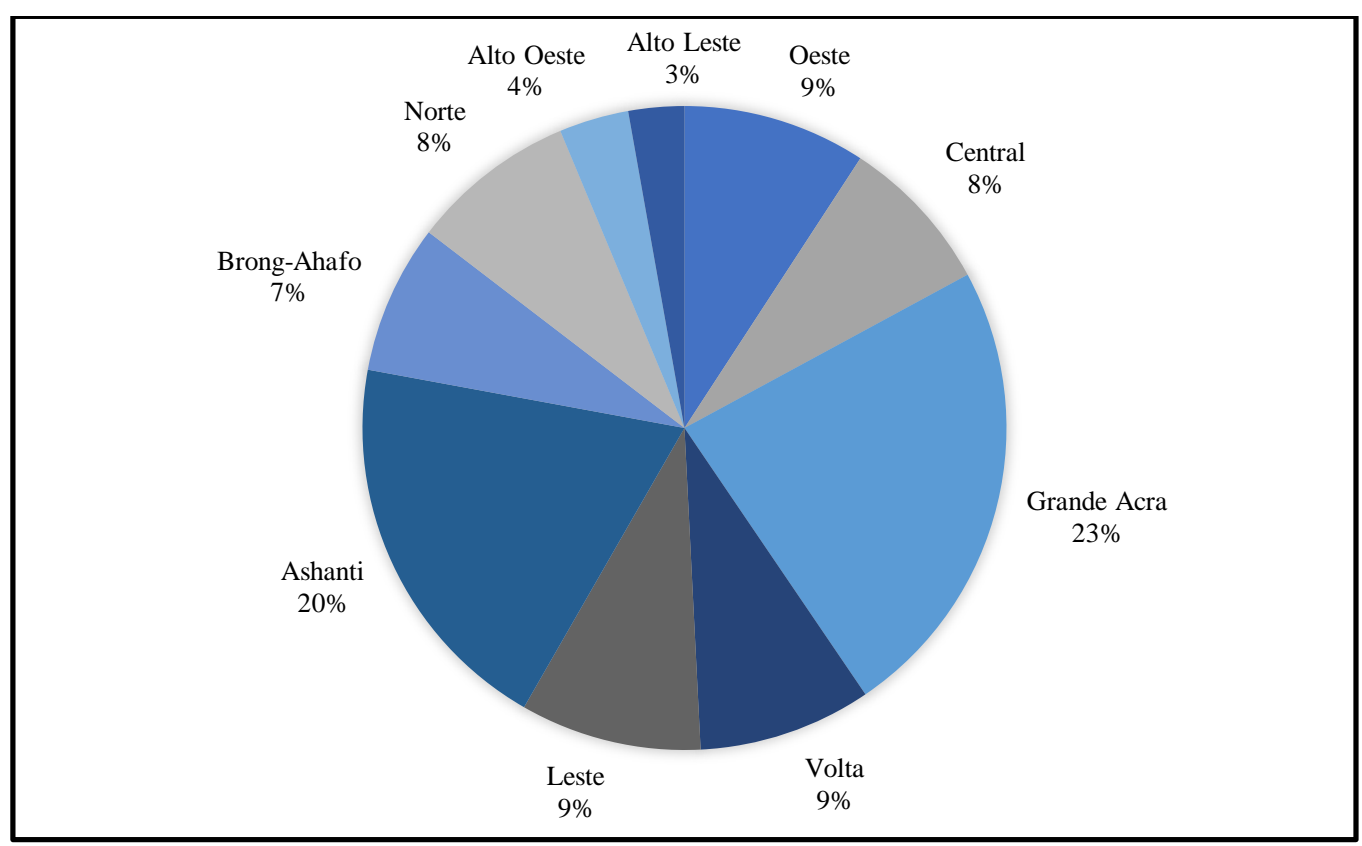

Fonte: SANTOS, 2017, p.106.

Atualmente, no universo das manufaturas ganenses, o CS é responsável principalmente pela produção de produtos alimentícios (Takoradi Flour Mils, Irani Brothers e Plot Enterprise), têxteis (Printex Ghana Ltd.), químicos e materiais de construção (Metalex Ltd., Azar Chemicals e HITTI Group) (GOODMAN AMC, 2016), revelando a presença do capital privado nacional na produção de bens de consumo não duráveis.

Altamente capitalizadas, tais manufaturas contam com uma atuação nacional e até mesmo internacional, operando exportações para países sem saída para o mar, como Níger e Burkina Faso. Para além disso, essas empresas estão, em sua maioria, estabelecidas há mais de duas décadas no país, o que denota relativa estabilidade dos empreendimentos.

Predominam nesse circuito os empregos formais diretos, registrados no governo, por mais que alguns serviços terceirizados contratem empresas com presença de mão de obra informal. No que diz respeito ao maquinário, é comum a importação de tecnologia, haja visto que o país não obteve êxito no desenvolvimento de indústrias nacionais de bens de capital.

No entanto, considerando a totalidade do setor industrial ganense, chama a atenção o fato de que $98 \%$ dos estabelecimentos são micro ou pequenas empresas. Tais empreendimentos integram um diversificado $\mathrm{Cl}$ que é formado principalmente por:

- manufatura de alimentos: produzem farinhas (de mandioca e banana), pães, biscoitos, chocolates e doces, frutas e tubérculos processados (como bananas, batatas e mandioca), peixes secos, molhos e temperos (especialmente pimentas), queijos, iogurtes e sorvetes;

- manufatura de bebidas: produzem sucos, refrigerantes, chás, além de engarrafarem água potável/mineral;

- manufatura têxtil (Figura 2): tecidos e roupas diversas (especialmente com as estampas e cortes tradicionais utilizados na África Ocidental e os panos kente, típicos de Gana), além de calçados (fechados ou sandálias, também com desenhos e estilos típicos da região);

- manufaturas de remédios e cosméticos: produzem remédios fitoterápicos, sabonetes, xampus, cremes (especialmente feitos a partir da manteiga karité, produzido no norte do país); 
- manufaturas de móveis: produzem cadeiras, mesas, camas, estantes, cômodas etc.

- oficinas de artesanato: produzem variados tipos de produtos desde cestas e vasos até instrumentos de trabalho, como martelos e teares.

Essas manufaturas atendem as demandas dos mercados locais e regionais e, eventualmente, do mercado nacional. É comum que as unidades de produção também funcionem como unidades de comércio, especialmente no caso da produção de móveis. Com relação ao maquinário, nota-se que os instrumentos mais simples - feitos de madeira e algumas ligas metálicas, como martelos, facas, teares, fogões e fornos (à lenha) por exemplo - chegam a ser produzidos pelos próprios trabalhadores, enquanto máquinas de maior nível de complexidade e que exigem o uso de eletricidade, geralmente são de segunda-mão, compradas em feiras e lojas do comércio varejista das grandes cidades, como Acra, Kumasi e Tamale (SANTOS, 2017).

Considerando que a maioria dos empreendimentos de manufatura são familiares, o aprendizado técnico dos trabalhadores é passado de geração em geração, especialmente no caso da produção de móveis, tecidos e sapatos. Os trabalhadores assalariados, por sua vez, são contratados como aprendizes quando as famílias não dão conta da demanda do mercado. Pode-se identificar o predomínio de homens nas atividades de produção de móveis e calçados, enquanto mulheres participam com maior frequência dos demais tipos de manufaturas.

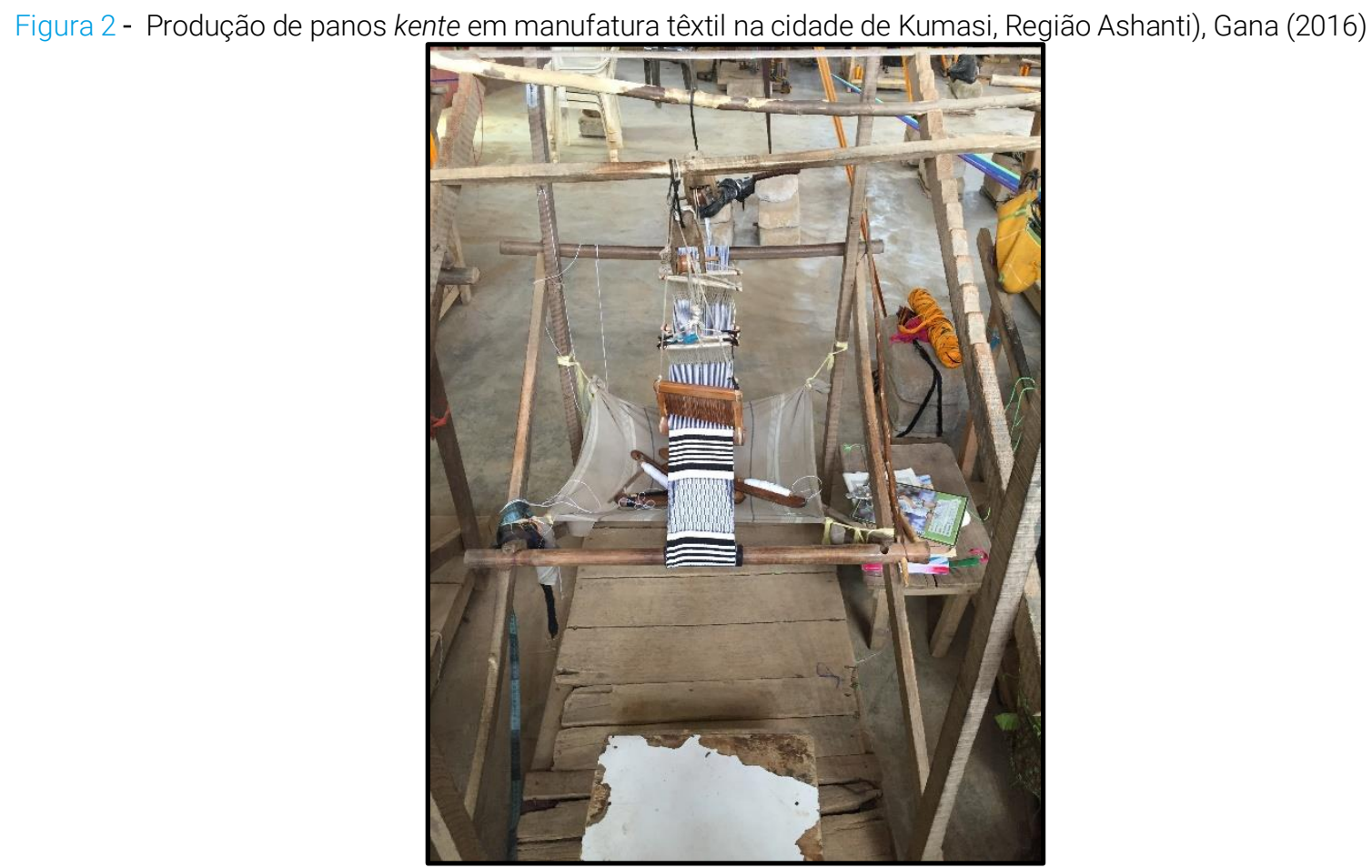

Fonte: elaboração do autor, 2016.

As relações que o $\mathrm{Cl}$ das manufaturas estabelece com as demais atividades da economia urbana ganense são variadas. Primeiramente, as mercadorias produzidas nesse circuito estão intimamente relacionadas ao setor de serviços, especialmente ao comércio: nesse caso, é possível que as próprias unidades produtivas funcionem também como loja, no entanto, o mais comum é que as mercadorias sejam vendidas nas ruas, em feiras ou até mesmo em grandes supermercados (como no caso dos produtos alimentícios). Para além disso, esse circuito consome matérias-primas e maquinários obtidos em estabelecimentos comerciais que possuem diferentes níveis de capitalização: ao mesmo tempo em que os proprietários de manufaturas do $\mathrm{Cl}$ podem comprar 
instrumentos vendidos em uma pequena mercearia do bairro, eles podem também comprar os mesmos instrumentos em uma grande rede varejista articulada ao mercado internacional.

Desse modo, tanto na entrada (compra de matérias-primas e instrumentos/máquinas), quanto na saída (comércio), o $\mathrm{Cl}$ da manufatura está intrinsicamente relacionado ao setor terciário da economia. Interessa agora entender como as atividades de serviços se organizam no espaço urbano ganense.

\section{Circuitos da economia e as atividades de serviços em Gana}

O comércio é uma das numerosas atividades que integram o setor de serviços e certamente o mais presente na paisagem urbana de Gana. Em 2014, a atividade foi responsável por $6 \%$ do PIB do país, tendo ficado atrás de transporte e armazenamento (11,7\%) e atividades financeiras e seguradoras (7,3\%), também integrantes do setor (INSTITUTE OF STATISTICAL, SOCIAL AND ECONOMIC RESEARCH, 2015). Com uma menor participação no total das riquezas geradas, figuram ainda: administração pública, segurança social e defesa (5,4\% do PIB); hotéis e restaurantes (5\%); atividades de serviço pessoal, social e comunitário (3,7\%); educação (3,6\%); serviços imobiliários e atividades de suporte administrativo e profissional (3,6\%); e informação e comunicação (2,3\%) (INSTITUTE OF STATISTICAL, SOCIAL AND ECONOMIC RESEARCH, 2015).

Assim como no caso da manufatura, o comércio é uma atividade que ocorre de diferentes maneiras nos espaços urbanos, segundo distintos níveis de capitalização e organização dos empreendimentos que funcionam, na maior parte das vezes, em condição de informalidade. De Bolgatanga (Região do Alto Leste) à Takoradi (Região Oeste), o comércio é feito em shopping centers, hipermercados e supermercados, bazares, barracas ao longo de estradas, em feiras e, também, por meio de vendedores ambulantes.

Tantos os shopping centers quanto os hipermercados e supermercados são estabelecimentos comerciais destinados principalmente às classes alta e média dos grandes centros urbanos do país e, em especial, de Acra. Muitas vezes essas empresas são também importadoras, suprindo uma demanda de consumo em torno de produtos estrangeiros de todos os tipos, em especial de bens de consumo duráveis e não duráveis não produzidos no país. No supermercado Melcon, fundado em 1989 por um grupo de empresários ganenses de origem indiana, pode-se observar a ampla presença de produtos de corporações do Norte Global, como Unilever, Coca-Cola, Nestlé, PepsiCo, Johnson \& Johnson, além de diversos produtos industrializados de origem asiática e sul-africana, e alguns produtos nacionais (inclusive produzidos pelo $\mathrm{Cl}$, como farinhas e biscoitos). Ainda figuram no país outras redes de varejo que pertencem a empresários ganenses, como: o A\&C Shopping, o Evergreen House and Supermarket, o Kwatsons e o Lulu Hypermarket. Dentre as redes estrangeiras que atuam no país destacam-se as sul-africanas Shoprite e Woolworths (SANTOS, 2017).

Essas redes de comércio varejista, assim como muitas lojas revendedoras de automóveis (e outros bens de consumo duráveis), podem ser entendidas como parte integrante do CS, já que possuem um elevado capital e uma estrutura organizacional bastante burocratizada. Os empregos aí são majoritariamente assalariados e formais. Muitas vezes essas empresas realizam um comércio diversificado (como no caso das redes de hipermercado e supermercado) e, outras vezes, realizam um comércio especializado, como no caso de empresas revendedoras de carros e motos: a loja Auto, por exemplo, é uma empresa que pertence à família ganense de origem libanesa Kalmoni, sendo responsável pela venda de aproximadamente $23 \%$ dos automóveis e $80 \%$ das motos consumidas no país (SANTOS, 2017). 
No entanto, novamente, é o Cl que se manifesta de forma mais frequente em Gana: atendendo à imensa maioria da população de menor poder aquisitivo, figuram os bazares, as feiras e o comércio ambulante.

Os bazares são estabelecimentos comerciais localizados muitas vezes dentro da própria moradia do vendedor. Nesses espaços comerciais são encontrados produtos importados e locais, de modo que predominam alimentos processados (como cereais, macarrão, refrigerantes, sucos, água engarrafada etc.) e produtos de higiene (sabonete, pasta, escova de dente etc.). Eventualmente também são comercializadas verduras e frutas. A organização do trabalho é frequentemente familiar e feminina.

Nos mercados é possível ter uma dimensão ainda mais nítida acerca do amplo espectro de mercadorias vendidas. Considerado um dos maiores mercados da África Ocidental, o Mercado Kejetia (Figura 3) - localizado em Kumasi (Região Ashanti) - organiza-se através uma setorização das mercadorias vendidas: existem áreas destinadas ao comércio de carnes (em especial com venda de frangos vivos e ovos nas calçadas) e peças de carne bovina e suínas penduradas em anzóis no teto de açougues; áreas destinadas ao comércio de grão como milho, painço e sorgo, além de inhame e mandioca (produzidos pela agricultura familiar do país); áreas de comércio de roupa, sendo que a maior parte delas são importadas de países asiáticos (China, Índia, Bangladesh, Vietnam, Tailândia e Camboja) e; áreas de comercialização de eletrônicos diversos (especialmente de segunda-mão). É importante notar ainda a convivência cooperativa - no espaço do mercado - entre as barracas nas calçadas e os vendedores ambulantes, o que denota diferentes condições de capitalização dos empreendimentos comerciais.

Em outro importante mercado ganense, o Makola - localizado em Acra -existe uma especialização comercial maior, uma vez que este se destina fundamentalmente a venda de produtos agrícolas, como: cebolas, tomates, mandioca, inhame, banana, manga, abacaxi, grãos diversos, peixes secos etc.

Figura 3 - Mercado Kejetia em Kumasi, Região Ashanti, Gana (2016)

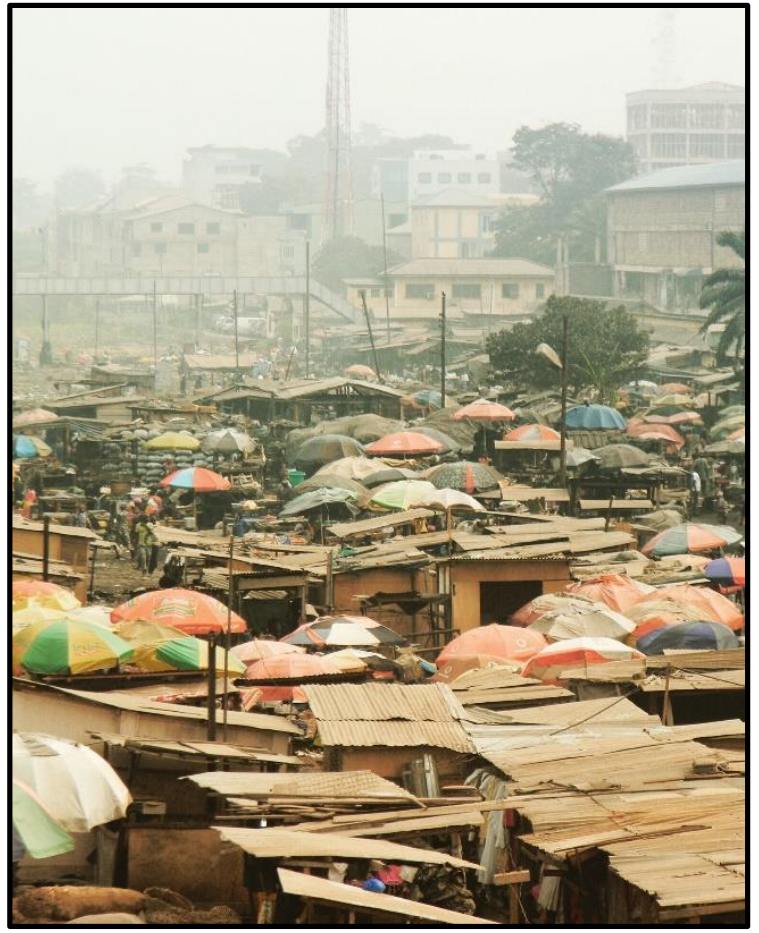

Fonte: elaboração do autor, 2016 
Com base nas entrevistas com trabalhadores do comércio, ficou evidente que as escalas de abrangência espacial das atividades são marcadamente distintas umas das outras. Os vendedores ambulantes cobrem uma área de mercado de consumo mais ampla do que os estabelecimentos comerciais fixos, como os bazares que, por sua vez, têm um mercado consumidor mais restrito, geralmente atraindo moradores do próprio bairro ou pessoas que passam pela localidade com frequência. Os mercados, no entanto, atraem consumidores de diferentes áreas da cidade e até do interior. De acordo com os depoimentos de alguns entrevistados:

Eu ando pela cidade inteira. Eu acordo cedo, às 5 da manhã. Eu ando por muitos bairros da cidade. Tudo a pé. Só volto para casa quando estou exausto. Quando as pessoas estão na rua, estou andando e vendendo. Eu conheço muitas pessoas aqui de Acra. Meus produtos são excelentes, grande parte da China, principalmente as roupas (Entrevistado 2, vendedor ambulante de Acra, em entrevista concedida em outubro de 2013).

Vendemos aqui produtos úteis para o uso diário: massas, molho de tomate, pão, sabão. Tem coisas de Gana e coisas importadas da China, Japão, Coreia. Quem compra aqui é principalmente as pessoas da vizinhança. Fico aberto até tarde (Entrevistada 37, vendedora de bazar de Acra, em entrevista concedida em março de 2016).

Eu vendo abacaxi aqui em Makola há dez anos. Todos os dias eu venho. Pessoas de toda a África vem comprar aqui. Os turistas de fora da África também sempre chegam aqui e pedem para fotografar as frutas. Eles sabem que aqui é um excelente lugar para comprar (Entrevistada 1, vendedora do mercado Acra, em entrevista concedida em março de setembro de 2013).

Uma característica notória da atividade comercial em Gana - e em grande parte dos países da África Ocidental - é a divisão por gênero: enquanto as mulheres são responsáveis pela comercialização dos produtos agrícolas e da indústria alimentícia, os homens comercializam os produtos manufaturados, como camisetas, calças jeans e produtos eletroeletrônicos e eletrodomésticos. Mesmo na porção norte do país, onde a população é majoritariamente islamizada, grande parte da atividade comercial recai sobre as mulheres, que não apenas comercializam em bazares, mas também nas ruas e beiras de estradas (SANTOS, 2017). Nessas atividades que integram o $\mathrm{Cl}$ do comércio urbano, a informalidade predomina e a organização familiar dispensa, recorrentemente, a necessidade de contratação de mão de obra assalariada.

O comércio é uma das atividades mais comuns do país, de maneira que aproximadamente 55\% dos estabelecimentos do setor terciário em Gana se ocupam com venda e revenda de produtos. Desses estabelecimentos, 29,2\% estão na Região da Grande Acra, 24\% na Região Ashanti e 10,3\% na Região Oeste (Gráfico 2). Assim como no caso das atividades do setor secundário, as atividades do setor terciário (não apenas o comércio, mas também os demais serviços) se realizam principalmente em micro (79\%) e pequenas empresas (18\%). Além disso, aproximadamente $70 \%$ das empresas do setor são relativamente novas, tendo sido fundadas entre 2005 e 2014 (GHANA STATISTICAL SERVICE, 2020).

No setor terciário, o capital nacional privado ganense desempenha um papel central não somente em atividades comerciais, mas também em diferentes tipos de serviços prestados, como o de transporte e armazenamento, que se desenvolve segundo uma organização menos burocratizada e por meio de reduzidos recursos financeiros.

As oficinas de reparos de bens de consumo duráveis também se destacam nas cidades do país: destinadas ao conserto de automóveis, maquinários diversos e produtos eletrodomésticos e eletroeletrônicos é, de certa forma, o que garante o aumento da vida desses produtos para a população ganense. Vale destacar também que grande parte dessas oficinas reparam objetos de segunda-mão que são importados dos países do Norte Global (SANTOS, 2018). Nas calçadas diante 
dessas oficinas, é comum ocorrer o próprio comércio das mercadorias consertadas: geladeiras, fogões, computadores, aparelhos de televisão, motocicletas etc. (SANTOS, 2017).

Gráfico 2 - Distribuição regional dos estabelecimentos de venda e revenda (em \%), Gana (2015)

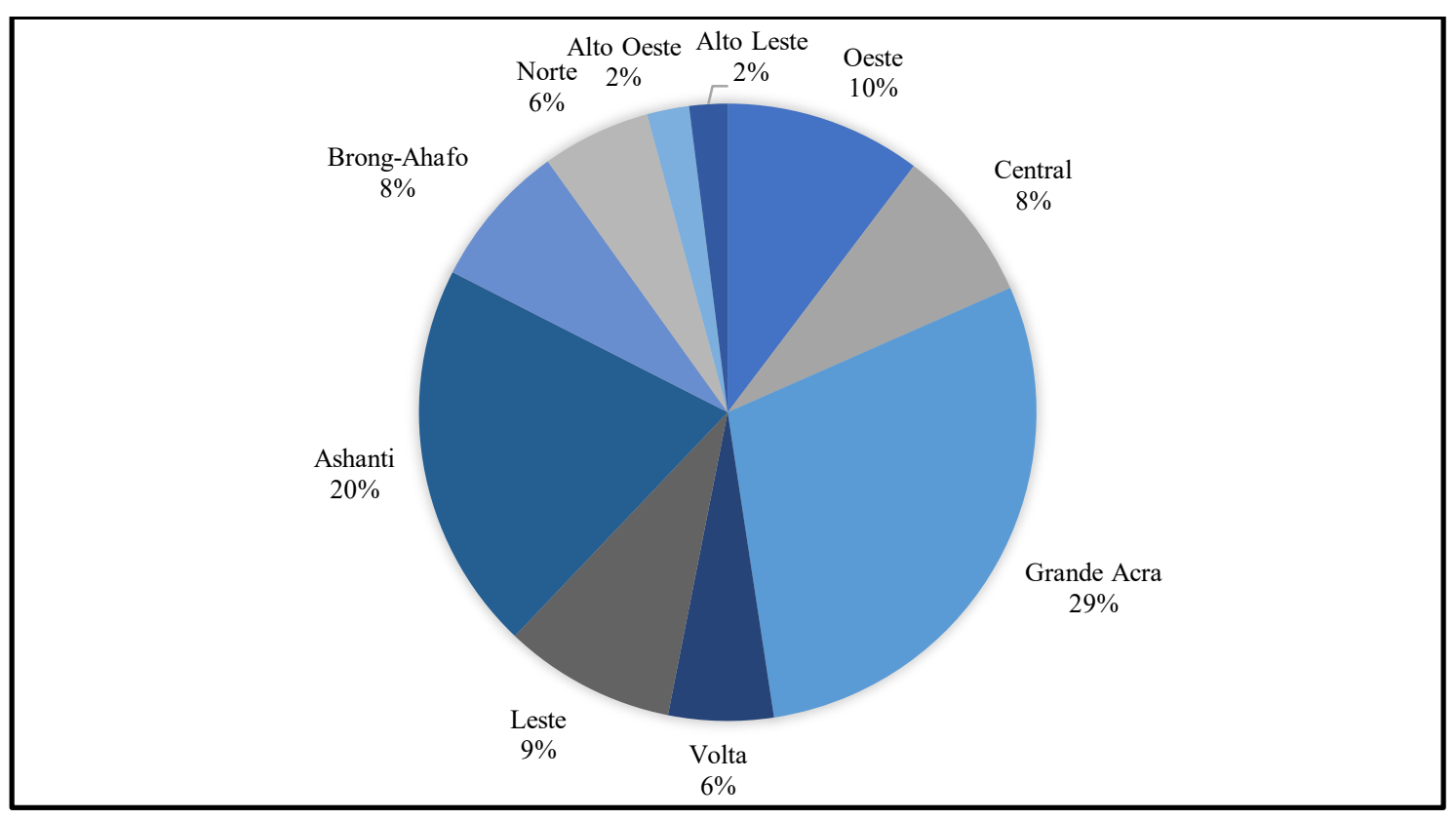

Fonte: SANTOS, 2017, p.110

Alguns serviços oferecidos nas cidades do país, contudo, integram fundamentalmente o CS e, inclusive, se caracterizam pela forte presença do capital estrangeiro. Analisando a cidade de Acra, o geógrafo estadunidense Richard Grant revela a forte presença do capital estrangeiro em imobiliárias e empresas de construção civil, geralmente sob controle de libaneses (13 empresas) e italianos (13 empresas), seguidos pelos britânicos (12), chineses (10), alemães (9), indianos (7) e estadunidenses (7) (GRANT, 2009). A presença estrangeira nas atividades financeiras também é notória, sobretudo no caso do banco sul-africano Standard Bank, que possui 30 agências e 40 caixas eletrônicos (distribuídos pelo território, mas concentrados nas cidades de Acra, Tema, Kumasi e Takoradi), apesar dos bancos nacionais (Bank of Ghana e Eco Bank) serem os mais difundidos pelo país. Já as atividades de seguradoras estão, em certa medida, sob controle de empresas ganenses altamente capitalizadas, como as Vanguard Group e a House of Duffor (GOODMAN AMC, 2016).

As atividades de serviços operam segundo diferentes níveis de capitalização e escala espacial. $\mathrm{O} \mathrm{Cl}$ predomina no setor terciário da economia ganense, podendo ser representado por variadas atividades, as quais respondem necessidades de trabalho e consumo da própria população, além das necessidades funcionais do próprio circuito inferior: ao mesmo tempo que o comércio ambulante, as feiras e as mercearias vendem produtos feitos por grandes corporações internacionais, as grandes redes varejistas comercializam produtos manufaturados por pequenas empresas ganenses. Assim, mais do que simplesmente categorizar as atividades em diferentes setores, é fundamental compreender a sua organização em circuitos e as diversas relações que elas estabelecem entre si na economia urbana. 


\section{Considerações finais}

Foram preocupações análogas que motivaram os esforços interpretativos de Hart e Santos no universo das cidades do Sul Global. Na década de 1970, ambos cientistas se viram diante de economias urbanas cuja organização dificilmente poderia ser explicada por modelos e teorias produzidas nos países desenvolvidos.

Por um lado, as noções de setor formal e setor informal foram bastante difundidas não apenas nas ciências humanas, mas também em institutos de pesquisa socioeconômica e organizações multilaterais, especialmente bancos. Nesse processo, as categorias de Hart reduziram-se a atribuições classificatórias e burocráticas, perdendo a complexidade analítica carregada nos estudos originais do antropólogo. Assim, ser uma atividade formal ou informal na economia urbana reduziuse a estar (ou não) registrado junto ao governo, o que pressupõe o pagamento de tributos ao Estado.

Por outro lado, menos difundida que as noções desenvolvidas por Hart, a teoria dos circuitos da economia urbana de Santos ampliou a complexidade analítica no que tange à interpretação da organização das atividades econômicas nas cidades do Sul Global. A formalidade e a informalidade deixam de ser um aspecto classificatório determinante na análise e se tornam uma das muitas características constitutivas dos circuitos. O fundamental para a teoria de Santos é identificar os níveis de organização e capitalização dos empreendimentos que podem integrar o circuito superior ou o circuito inferior.

Em Gana, observa-se a existência de um circuito inferior predominante no espaço urbano e notoriamente diversificado, incorporando atividades de pequenas manufaturas e serviços. Essas atividades além de gerar numerosos empregos no país, também dão conta das demandas de consumo da população. Deve-se notar que a maior parte desse circuito opera em situação de informalidade, o que dificulta o acesso dos empreendimentos a linhas de crédito em bancos. A escala de atuação do $\mathrm{Cl}$ ganense é variável, podendo ser local ou até mesmo regional e nacional, dependendo da atividade. Ao mesmo tempo, o circuito superior possui uma presença mais pontual no país, sendo representado por atividades extremamente capitalizadas e com acesso às tecnologias mais modernas.

Por fim, além de classificar e caracterizar a organização das diversas atividades da economia urbana ganense, este artigo preocupou-se em identificar e analisar o conjunto de relações que elas estabelecem entre si, mostrando os níveis de cooperação nos quais os circuitos operam. 0 dinamismo da economia nas cidades de Gana é fundamentalmente o dinamismo que a pobreza impõe nas cidades do Sul Global, de modo que o circuito inferior - tão presente nas cidades africanas, latino-americanas e asiáticas - é um produto das necessidades de trabalho e consumo da população urbana. 


\section{Referências}

BANCO MUNDIAL. (2020). Disponível em: https://data.worldbank.org/country/ghana Acesso em: 15 jan. 2020.

BOAHEN, A. A. (2010). O colonialismo na África: impacto e significação. In: BOAHEN, A. A. (editor). História geral da África V. Brasília: UNESCO.

BOATENG, E. (1959). A geography of Ghana. Cambridge: Cambridge University Press.

GEERTZ, C. (1973). The Interpretation of Cultures. Nova Iorque: Basic Books

GHANA STATISTICAL SERVICE. (2020). Disponível em: http://www.statsghana.gov.gh Acesso em: 10 jan. 2020.

GOODMAN AMC. (2016). Disponível em: http://www.goodmanamcllc.com Acesso em: 15 fev. 2016.

GRANT, R. (2015). Africa: geographies of change. Nova lorque: Oxford University Press.

GRANT, R. (2009). Globalizing city: the urban and economic transformation of Accra, Ghana. Nova Iorque: Syracuse University Press.

GLASER, B.G and STRAUSS, A. L. (1967). The discovery of Grounded Theory: strategies for Qualitative Research. Chicago: Aldine Publishing Company.

HART, K. (1973). Informal Income Opportunities and Urban Employment in Ghana. The Journal of Modern African Studies. Issue 1, Volume 11, p. 61-89.

HUTCHFUL, E. (2002). Ghana's adjustment experience: the paradox of reform. Oxford: James Currey. INSTITUTE OF STATISTICAL, SOCIAL AND ECONOMIC RESEARCH (2015). Disponível em: http://www.isser.edu.gh Acesso em: 10 ago. 2015.

KIPRÉ, P. (2010). O desenvolvimento industrial e o crescimento urbano. In: MAZRUI, A (ed.). História geral da África: África desde 1935. São Paulo: Cortez; Brasília: UNESCO, 2011.

M'BOKOLO, E. (2011). África negra: história e civilizações. São Paulo; Salvador: Casa das Áfricas; Edufba. Volume 2.

OSEI, F. B., STEIN, A. NYADANU, S. D. (2018). Spatial and temporal heterogeneities of district-level typhoid morbidities in Ghana: A requisite insight for informed public health response. PLoS ONE, 13:11. RIMMER, D. (1992). Staying poor: Ghana's political economy, 1950-1990. Oxford: Pergamon Press, 1992.

ROY, A. (2009). The 21 st-Century Metropolis: New Geographies of Theory. Regional Studies, 43:6, 819830.

SANTOS, K. L. (2017). Pontas em Circuito: As inserções de Gana na Divisão Internacional do trabalho contemporânea. São Paulo: FFLCH (Tese em Geografia Humana).

SANTOS, K. L. (2018). Ouro para fora, lixo para dentro: as inserc,ões de Gana na divisão internacional do trabalho contemporahea e a recommodizac,ão da economia. Geousp - Espaço e Tempo (Online), 22:3, p. 607-622.

SANTOS, M. (2004). O espaço dividido: os dois circuitos da economia urbana dos países subdesenvolvidos. São Paulo: EDUSP.

WALLERSTEIN, I. (2007). World-system analysis: an introduction. Durham; London: Duke University Press.

YANKSON, P. W. K. (2006). Urbanization, industrialization and national development: challenges and prospects of economic reform and Globalization. Legon: University of Ghana, 2006. 